(c)

\title{
EL DESENCANTO DE LOS COMUNITARIO. TRES MODOS DE DANZA EN NIETZSCHE
}

\author{
THE DISENTCHANMENT OF THE COMMUNITY. THREE MEANINGS \\ OF DANCE BY NIETZSCHE
}

Victoria Mateos de Manuel

Facultad de Filosofía, UCM

(victoriamateos@ucm.es)

http://orcid.org/0000-0002-3483-7138

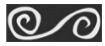

DOI: https://doi.org/10.32621/acotaciones.2019.43.04 ISSN 2444-3948

Resumen: En este artículo propongo una lectura de los usos de la danza en Nietzsche como un síntoma del progresivo desencanto con lo comunitario y lo político en este autor. En concreto, a través de la metáfora de la danza en Nietzsche, voy a plantear tres modos de la experiencia dionisíaca, los cuales discurren desde la comprensión del éxtasis como celebración de lo comunitario hasta la soledad radical de la sabiduría dionisíaca. En primer lugar, siguiendo le lectura de Sloterdijk, nos encontramos con la interpretación socialista del inicial dionisismo nietzscheano en El nacimiento de la tragedia: la danza permite «la alianza del hombre con el hombre» $\mathrm{y}$ «lo revela miembro de una comunidad superior». En segundo lugar, la inicial esperanza política de lo dionisíaco se transforma en una pequeña comunidad apolítica en el capítulo «La canción del baile» de Así babló Zaratustra a través de la imagen del grupo de bailarinas en el bosque. En tercer lugar, también en Así habló Zaratustra, aparece la metáfora de la «estrella danzarina», la cual nos habla de una suerte de soledad cósmica y una experiencia dionisíaca disidente. 
Palabras Clave: Dionisíaco, danza, comunidad, La canción del baile, estrella danzarina, Nietzsche.

Abstract: In this article I propose a reading of Nietzsche's uses of dance as a symptom of his progressive disenchantment with politics and the community. Concretely, by making use of Nietzsche's metaphor of dance, I am going to propose three ways of the Dionysian experience in this author, which run from the comprehension of ecstasy as a communal experience to a radical solitude. Firstly, following Sloterdijk's reading, we find a socialist interpretation of Nietzsche's initial Dionysism in Die Geburt Jer Tragödie: dance allows the alliance among men and manages a «superior community». Secondly, we find in Also sprach Zarathustra that the Dionysian experience turns into a small communal apolitical experience. I am referring to the chapter «Das Tanzlied» of Also spracts Zarathustra, where there is a small group of female dancers in the forest. Finally, we also find a second dance metaphor in Also sprach Zarathustra: der tanzende Stern. It expresses a cosmic solitude and a dissident Dionysian experience.

Key Words: Dionysian, dance, community, Das Tanzlied, tanzender Stern.

Sumario: 1. Introducción. 2. El socialismo estético del dionisismo en $E l$ nacimiento de la tragedia. 3. Lo dionisiaco como ligereza en «La canción del baile». 4. La soledad cósmica de la estrella danzarina. 5. Conclusiones. 6. Bibliografía. 7. Notas.

Copyright: (C) 2019. Este es un artículo abierto distribuido bajo los términos de una licencia de uso y distribución Creative Commons 4.0 Internacional (CC BY 4.0)

Victoria Mateos es profesora asociada en el Departamento Filosofía y Sociedad de la Facultad de Filosofía de la Universidad Complutense de Madrid. Doctora Europea en Filosofía por la UCM con Premio Extraordinario de Doctorado 2018. He sido becaria FPU en el Instituto de Filosofía del CSIC y he realizado estancias de estudios e investigación en la Facultad de Filosofía de la Universidad Humboldt de Berlín, la Facultad de Ciencias Sociales y Políticas de la Universidad Libre de Berlín, el Departamento de Estudios de Teatro y Danza de la Universidad Libre de Berlín y el Departamento de Danza de la Universidad París 8 Saint Denis. 


\section{INTRODUCCIÓN}

No existe un único modo en que lo dionisíaco tenga lugar. La experiencia dionisíaca, como el Dios que le da nombre, es una experiencia con múltiples caras. ${ }^{1}$ Este carácter polimórfico de lo dionisíaco se observa también en el interior de la obra nietzscheana. Aunque Nietzsche consagró numerosas páginas de sus textos a desentrañar lo dionisíaco, su significado siguió siendo para el autor un enigma y Nietzsche no quedó indiferente a la ambigüedad y abundancia que el término «Dioniso» conlleva. Es extremadamente difícil definir qué significa exactamente la categoría estética de la embriaguez y en qué circunstancias tiene lugar. Y así lo dejó señalado Nietzsche en 1886 en Ensayo de autocrítica, texto que criticaba las presuposiciones iniciales de El nacimiento de la tragedia (1872):

[...]; había un espíritu ahíto de necesidades extrañas y aún no articuladas en lenguaje alguno, una memoria henchida de interrogante, experiencias, secretos ocultos, a los cuales se añadía, como un problema nuevo, el nombre de Dioniso; [...] Pues para los filólogos en este terreno está casi todo por descubrir y exhumar. Sobre todo el problema de que aquí subyace un problema; y de que, mientras no tengamos respuesta a la pregunta «¿qué es lo dionisíaco?», los griegos seguirán siendo absolutamente incomprensibles e inimaginables... (eKGWB/GT-Selbstkritik-3; Nietzsche, 2007, pág. 87)

Este carácter escurridizo de lo dionisíaco nos lleva a intentar estudiarlo no de una manera genérica, sino a través de una de las expresiones estéticas que Nietzsche en El nacimiento de la tragedia adscribe a este «estado estético de la naturaleza» (eKGWB/GT-2; Nietzsche, 2007, págs. 108-109) ${ }^{2}$ : la danza, la cual es una imagen recurrente del pensamiento nietzscheano. ${ }^{3}$ Lamothe (2003) ha leído el uso de esta metáfora en Nietzsche como un modo de reivindicación del cuerpo -el mandato zaratustriano «permaneced fieles a la tierra» (eKGWB/Za-I-Vorrede-3; Nietzsche, 1981, pág. 34)- frente al ascetismo cristiano. ${ }^{4}$ Asimismo, Luis E. de Santiago Guervós (2004, pág. 516-521) nos presenta «la manifestación artística de la danza» en Nietzsche como un «recurso estético» que describe tanto la revitalización del ejercicio del pensamiento en este autor frente a la «filosofía de cátedra» (Kathederphilosophie) ${ }^{5}$, como el 
«espíritu dionisíaco» y el «espíritu de la ligereza» propios del superhombre nietzscheano y la transvaloración de todos los valores, conceptos claves en el aparato conceptual nietzscheano.

Sin ánimo de soslayar estas dos destacables, legítimas y fundamentadas lecturas sobre el papel de la danza en el pensamiento nietzscheano, en este artículo se sumará otra posible interpretación de este tema, la cual nos permite leer lo dionisíaco desde una perspectiva política. En este texto sostendré la tesis de que la evolución en las imágenes y metáforas (Denkbilder, siguiendo el concepto inaugurado por Benjamin en 1923) de la danza en Nietzsche entre su uso en El nacimiento de la tragedia (1872) y Así habló Zaratustra (1883-85) es síntoma del progresivo desencanto en Nietzsche con el inicial carácter comunitario y político de la experiencia dionisíaca. Para desarrollar esta idea, atenderemos a tres figuras de la danza en Nietzsche en estas dos obras: la «comunidad superior» de El nacimiento de la tragedia, el capítulo «La canción del baile» de Así babló Zaratustra y la metáfora de la «estrella danzarina» en Así babló Zaratustra.

El SOCIALISMO ESTÉtico DEL DIONISISMO EN EL NACIMIENTO DE LA TRAGEDIA

Los dos modelos de danza que ejemplifican la experiencia de lo dionisíaco en El nacimiento de la tragedia son los episodios de coreomanía que tuvieron lugar en la Edad Media: los bailarines del «día de San Juan» y los bailarines de «San Vito», casos que recuerdan a Nietzsche lo que pudieron haber sido «los coros báquicos de los griegos» (eKGBW/GT-1; Nietzsche, 2007, pág. 105). ${ }^{6}$ Lo dionisíaco, en este sentido, viene determinado como una experiencia colectiva de embriaguez a través de la cual se constituye una comunidad. Sin embargo, no se trata de una comunidad que venga articulada por un vínculo o un preposicional «entre», es decir, por un modo de quedar conectados unos individuos separados a través de un enlace o intercambio que funcione como argamasa o pegamento de lo comunitario. En la experiencia de lo dionisíaco no se trata de un vínculo en sentido propio, sino de una fusión entre individuos. Nietzsche habla de la desaparición instantánea de toda distancia o escisión entre sujetos, de la anulación momentánea de la individualidad, pues lo dionisíaco no entraña un vínculo relacional que permita a cada 
individuo conservar su «yo», sino que hace desaparecer por instantes la idea de que somos entes separados. La comunidad dionisíaca, por lo tanto, se genera a través de la fusión o comunión entre sujetos, es decir, por medio de la desaparición del principio de individuación (principium individuationis):

[...] cualquiera se siente no sólo unido, reconciliado, fundido con su prójimo, sino Uno, como si el velo de Maya hubiera sido desgarrado y sus jirones revoloteasen de un lado a otro ante la misteriosa unidad originaria. (eKGBW/GT-1; Nietzsche, 2007, pág. 105)

En consecuencia, la danza es interpretada como una expresión de lo extático y es una experiencia multitudinaria que hace desaparecer las fronteras entre los seres humanos, que «renueva la alianza del hombre con el hombre» y en la cual «se derriban todas las rígidas y hostiles limitaciones que la miseria, la arbitrariedad o la «frívola moda» han impuesto a los hombres» (eKGBW/GT-1; Nietzsche, 2007, pág. 107). Se rompen los límites o fronteras que discurren entre los seres humanos en la vida cotidiana, consiguiendo generar un sentimiento de unidad o fusión entre ellos. Lo dionisíaco es, por lo tanto, una noción que sirve para construir y amalgamar una comunidad a través de la emoción extrema. Lo dionisíaco se trata de «una realidad plenamente embriagada que, a su vez, no sólo no se preocupa del individuo, sino que, incluso, persigue su aniquilamiento y liberación mediante un sentimiento de unidad mística» (eKGBW/GT-2; Nietzsche, 2007, pág. 108).

Además, esta pérdida de individualidad y la exaltación de lo irracional a través de la experiencia dionisíaca no tienen un sentido patológico en este filósofo. Nietzsche considera que los bailes de San Vito o San Juan no han de ser considerados perturbaciones del alma colectiva, sino expresiones de armonía y reconciliación, posicionándose con ello contra quienes «se burlan de ellos como si no fueran más que «enfermedades populares» (eKGBW/GT-1; Nietzsche, 2007, pág. 105).

Eso sí, si bien la experiencia dionisíaca no tiene la connotación despectiva de fenómeno insalubre, por el contrario, sí tiene la potencia del contagio: todo aquel que participa de la multitud se ve impelido, arrastrado, conminado, conmovido, dominado a participar, disfrutar y sucumbir en lo dionisíaco. Lo dionisíaco se presenta como un vínculo 
catártico y colectivo en el que no se decide participar sino al que, simplemente, se sucumbe.

La excitación dionisíaca posee la capacidad de transmitir a toda una masa de gente [Madde] el don artístico de verse envuelto en esta procesión de espíritus y de saberse en comunión íntima con ella. [...] aquí nos topamos ya con una individualidad que, penetrando en una naturaleza extraña, renuncia a sí misma [Aufgeben des Individums]. Un fenómeno que, de hecho, se extiende como si fuera una epidemia [epidemisch]: toda una multitud [eine ganze $S_{c h a r}$ ] se siente mágicamente transformada bajo este influjo. (eKGWB/GT-8; Nietzsche, 2007, pág. 147)

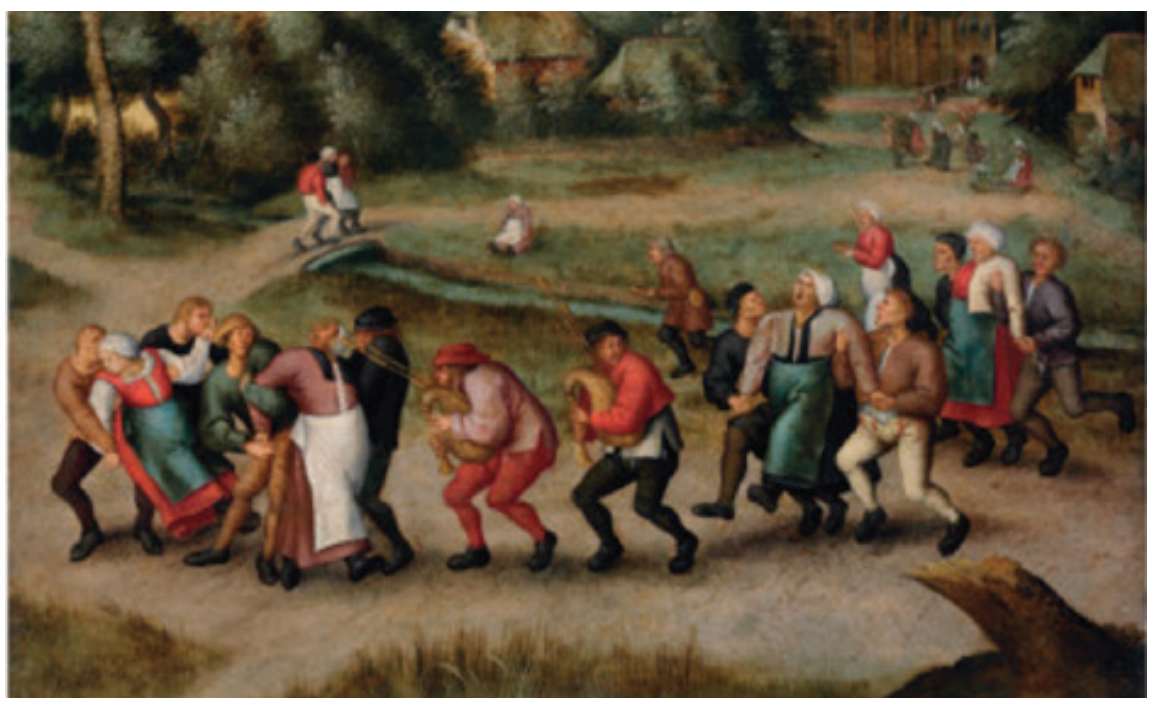

Figura 1. Peter Brueghel the Younger (1592), The Saint John's Dancers in Molenbeeck [Oil on panel], $30 \times 62,5 \mathrm{~cm}$, Christie's (Property from a private european collection). Wikimedia Commons.

Asimismo, Sloterdijk lee esta exposición de la experiencia dionisíaca en El nacimiento de la tragedia no solo en clave comunitaria y festiva, sino principalmente en clave política, pues hay un fin estructurador en la embriaguez: pergeñar una «comunidad superior». El éxtasis puede entenderse como un recurso hacia el socialismo estético: «Mientras canta y baila, el hombre se revela miembro de una comunidad superior», «la 
naturaleza vuelve a festejar su reconciliación con su hijo pródigo, el hombre», «si transformáramos el «himno de la alegría» de Beethoven [...] podríamos acercarnos al sentido de lo dionisiaco» (eKGBW/GT-1; Nietzsche, 2007, pág. 107). La famosa exhortación marxiana «proletarios del mundo, ¡uníos!», se transformaría en El nacimiento de la tragedia en una alianza cósmica entre los hombres a través de lo dionisíaco, que es «evangelio de la armonía universal» (eKGBW/GT-1; Nietzsche, 2007, pág. 107). Ya no sería una clase social o un principio antropológico los criterios estructuradores de lo comunitario, sino que es una comunión con lo informe e irracional que nos acecha aquello que es capaz de articular una ligazón entre los hombres.

Ésta es la opción de Nietzsche -por más que el lector no dé crédito a lo que ven sus ojos. [...], hoy podría considerarse El nacimiento de la tragedia como un manifiesto socialista capaz de resistir la comparación con $E l$ manifiesto comunista. La obra podría interpretarse como el escrito programático de un socialismo estético, como la Carta Magna de una fraternité cósmica; [...] (Sloterdijk, 2000, pág. 67)

En un sentido genérico, como señala Sloterdijk, estas afirmaciones nietzscheanas sobre la naturaleza de lo dionisíaco podrían entenderse como una propuesta estética socialista. Sloterdijk lo presenta echando mano de un vocabulario más mordaz basado en un andamio sexo-político dicotómico: el inicial dionisismo, en cuanto experiencia de embriaguez y fusión colectiva, de «orgiástica sexualidad del culto a la primavera», se trata de una suerte de «vulvocracia socialista», «bobada izquierdo-ecologista de todos abrazados», «obscena confusión»o «disolución dionisíaca-femenina» que produce «náusea»y, ante la cual, se necesita la construcción de un «dique dórico» o «principio masculino de orden»: lo apolíneo (Sloterdjik, 2000, pág. 67-68).

A estas consideraciones de Sloterdjik, añadiría que no solo nos encontramos en esta caracterización de la danza dionisíaca ante una propuesta de "socialismo estético», sino que, en un sentido estrecho, tiene también lugar una incipiente teoría estética de la multitud en El nacimiento de la tragedia, la cual se sitúa en coherencia con otras manifestaciones teóricas y literarias de la segunda mitad del siglo XIX sobre el fenómeno de las masas. 
En primer lugar, el carácter orgiástico que Nietzsche presupone a la muchedumbre dionisíaca -Nietzsche hace uso de los términos masa (Masse) y multitud (Schar) - lo encontramos inicialmente en la literatura contemporánea en Baudelaire, para quien la experiencia de la multitud en la ciudad moderna tenía un claro matiz sexual. Como narra en el texto «Las muchedumbres» de Spleen de París (1869), la experiencia de la multitud es equiparada al placer erótico, pues, al compartir un espacio tan estrecho y hormigueante con desconocidos, hacerse partícipe de la multitud es como hacerse partícipe de una sexualidad transgresora. En Baudelaire, como en el caso del orgasmo en el que el yo se disuelve por instantes, la erotización de las masas aparece como metáfora de la fusión con la alteridad: «como esas almas errantes en busca de un cuerpo, entra, cuando quiere, en la personalidad de cada cual», «el pensativo obtiene una singular embriaguez de comunión universal», «aquel que se desposa fácilmente con la muchedumbre conoce gozos febriles», «lo que los hombres llaman amor es muy pequeño, muy restringido y muy débil, comparado con esta inefable orgía, con esta santa prostitución del alma que se da por completo [...] a lo desconocido que pasa» (Baudelaire, 2016, págs.. 65-68). ${ }^{7}$

Nietzsche prosigue esta línea de lectura afirmativa de Baudelaire que encumbraba la experiencia orgiástica de la multitud. Para Nietzsche, la experiencia colectiva dionisíaca no es una forma de caos o una patología sino, por el contrario, expresión de armonía, un modo de recuperación del hermanamiento entre seres humanos, una expresión fraternal. Lo dionisíaco, si bien irrumpe y altera el orden social del cotidiano, genera comunidad y no una preocupante congregación anárquica. La danza colectiva dionisíaca no es en El nacimiento de la tragedia un fenómeno disgregador, sino un proyecto estético de conciliación fraterna.

No obstante, en el siglo XIX aparece también otra lectura del fenómeno de las multitudes que es, por el contrario, crítica con su potencial comunitario y denuesta esta expresión colectiva, así como el poder redentor colectivo que Nietzsche le concede al fenómeno báquico. Este planteamiento es deudor del libertinismo erudito del siglo XVII de Gabriel Naudé en Consideraciones políticas sobre los golpes de Estado (1639). En este texto la muchedumbre es ya calificada de voluble y «estúpida multitud», «inferior a las bestias, peor que las bestias y cien veces más necia que las mismas bestias» (Naudé en Lomba, 2014, pág. 110). 
En el siglo XIX se trata, por un lado, de la crítica a la Comuna de París de 1871 por los escritores Edmond y Jules de Goncourt en su Diario -escrito en la década de 1870-, en el que conforman un imaginario en el que la masa, lo monstruoso y lo femenino irracional confluyen como muestras de caos y peligro sociales. ${ }^{8}$ Por otro lado, nos encontramos ya no con expresiones literarias -como en los casos de los hermanos Goncourt y Baudelaire-, sino con la específica inicial teoría de masas con Gustave Le Bon (Psychologie des Foules, 1895) e Hippolyte Taine (Les Origins de la France Contemporaine, 1878). El carácter contagioso que Nietzsche atribuye a lo dionisíaco es teorizado específicamente por Le Bon, quien considera que las masas tienen un carácter ilógico, enfermizo y degradante, pues en la anulación del individuo no hay un suerte de comunión extática, sino una simple y peligrosa pérdida de identidad. La multitud no es, en consecuencia, una «comunidad superior» como en Nietzsche, sino un modo de «razonamiento inferior» (Laclau, 2005, pág. 41-45). Como señala Susan Barrow, los fenómenos masivos, entendidos con tintes peyorativos, son asimilados a los alcohólicos y las mujeres en el siglo XIX y, para Taine, las multitudes son expresión de degeneración, de la disolución de las instituciones políticas y sociales y de la falta de contención social dentro de unos límites razonables (Laclau, 2005, pág. 53). El individuo siempre sale perdiendo en la multitud, lo cual era para Nietzsche precisamente su ganancia: poder anularse en la expresión colectiva. Para estos autores, por el contrario, no hay emancipación en el éxtasis colectivo. Tan solo degradación tumultuosa y peligrosa acefalía.

\section{LO DIONISIACO COMO LIGEREZA EN «LA CANCIÓN DEL BAILE»}

La comprensión del arrobamiento dionisíaco como una experiencia comunitaria no se encuentra solo en El nacimiento de la tragedia, sino que también es reforzada por la escena de danza que se expone en el capítulo «La canción del baile» de Así babló Zaratustra. En ella vamos a observar dos diferencias fundamentales respecto a las iniciales presuposiciones del dionisismo: la experiencia dionisíaca ya no se trata de un fenómeno masivo, sino que remite a un discreto grupo femenino de participantes que, además, llevan a cabo su danza en el bosque, alejadas del ámbito de la ciudad. Por ello, no se trata ya de un fenómeno que pudiese ser expresamente calificado de político, ya que acontece fuera 
de la polis. Asimismo, la cualidad que define lo dionisíaco no es ahora la embriaguez, sino principalmente la ligereza, valor que es opuesto al del «espíritu de la pesadez» (Geist der Schwere) (eKGWB/Za-II-Tanzlied; Nietzsche, 1981, pág. 162). ${ }^{9}$

La escena de baile expresada en este capítulo es la siguiente (eKGWB/ Za-II-Tanzlied; Nietzsche, 1981, págs. 162-164). Atardece y Zaratustra se encuentra paseando con sus discípulos por el bosque, un escenario que es propio del Romanticismo (véase Argullol, 1991) y que también aparece en El sueño de una noche de verano de William Shakespeare (1605), texto en el que, siguiendo leyendas medievales, Titania, esposa de Oberón, se entrega a alegres danzas con su séquito de hadas, espetando a Oberón que solo debe permanecer con ellas si está dispuesto a participar en el baile. En un claro del bosque, Zaratustra encuentra un grupo de muchachas bailando en corro. Se trata de mujeres que son «ligeras» (ihre Leichten) con "pies de muchacha de hermosos tobillos» (MädchenFüßen mit schönen Knöcheln), las cuales dejan de bailar cuando vislumbran a Zaratustra y sus discípulos, a quienes confunden con el «espíritu de la pesadez» (Geist der Schwere), planteándose una contraposición entre el pensamiento tedioso y grave, considerado masculino, y el vitalismo jovial, que recae en el polo femenino. Zaratustra declara ante las bailarinas que él no es «ningún aguafiestas, ningún enemigo de muchachas» (eKGWB/Za-II-Tanzlied; Nietzsche, 1981, pág. 163). Por ello, canta una canción en que se burla del «espíritu de la pesadez», la cual bailan al unísono Cupido y las mujeres.

La canción de Zaratustra y el baile de las muchachas son un canto a la sabiduría. Sabiduría que podemos considerar dionisíaca porque según dice Zaratustra- se esconde tras el velo de Maya: «¡Ah sí!, ¡la sabiduría! Tenemos sed de ella y no nos saciamos, la miramos a través de velos, la intentamos apresar con redes» (eKGWB/Za-II-Tanzlied; Nietzsche, 1981, pág. 164). Tenemos, pues, un nuevo escenario de lo dionisíaco a través de esta escena de danza: la sabiduría dionisíaca se presenta ahora como una experiencia de lo ligero que tiene lugar en una pequeña comunidad apartada de la ciudad. Es una escena donde lo extático y vital se concretan a través de lo armónico y liviano: la danza en común muestra una comunidad bien avenida. No se trata ya del éxtasis violento de los ritos de las Bacantes, quienes poseídas por Dioniso ejecutan el sparagmos y la omofagia. Por el contrario, las danzas de mujeres en el bosque conforman ahora un imaginario cándido, suave, harpado. 


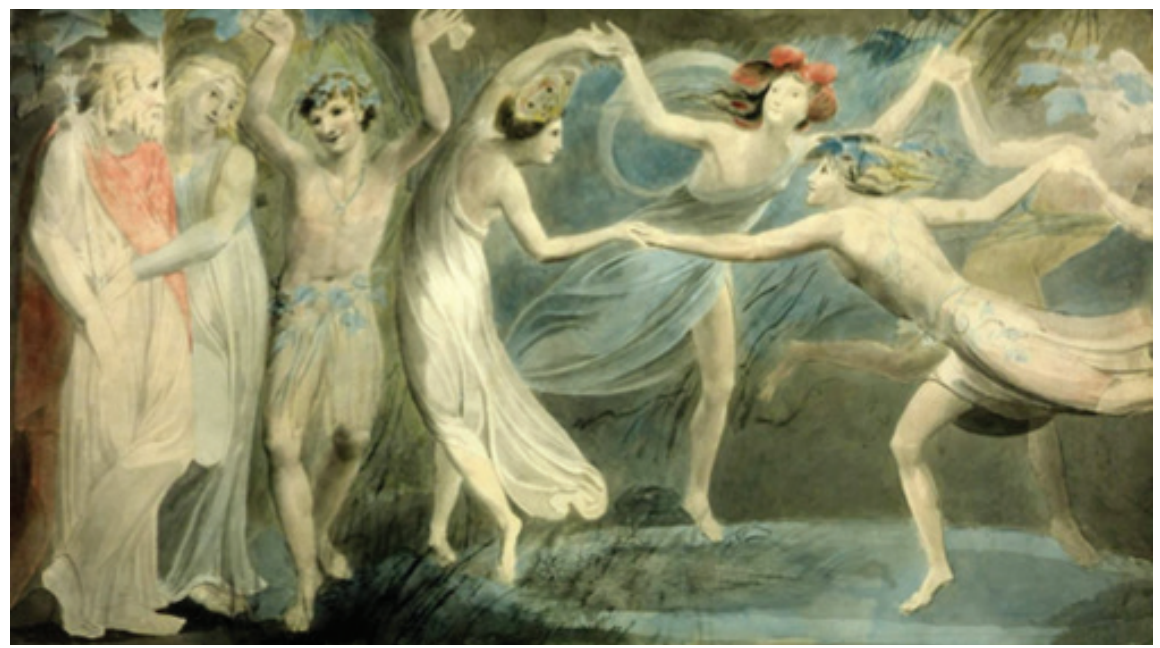

Figura 2. William Blake (h. 1786), Oberon, Titania and Puck with Fairies [Watercolour and graphite on paper], $475 \times 675 \mathrm{~cm}$, Tate, London. Wikimedia Commons.

Esta armonía dionisíaca que se presupone en la metáfora de la danza grupal, es una imagen que aparece inicialmente en el Renacimiento, a través de la reescritura iconológica de un tema presente en el canto XVIII de Ilíada de Homero, donde la paz de la ciudad, a través del escudo de Aquiles realizado por Hefesto, es descrita como un baile festivo comunitario. En la ciudad en paz

se celebraban bodas y festines: las novias salían de sus habitaciones y eran acompañadas por la ciudad a la luz de antorchas encendidas, oíanse repetidos cantos de himeneo, jóvenes danzantes formaban ruedos, dentro de los cuales sonaban flautas y cítaras, y las matronas admiraban el espectáculo desde los vestíbulos de las casas. (Homero, 1972, págs. 320-321)

Éste tópico literario se representa en los Efectos del Buen Gobierno de los frescos de Ambrogio Lorenzetti en el Palazzo Público de Siena (1338-1339). Lorenzetti pintó «alegóricamente los deberes y virtudes de la nueva república de Siena, gobernada por un pequeño número de ciudadanos, elegidos por períodos cortos de tiempo para evitar los males de las monarquías hereditarias y de las tiranías» (González García, 2016, pág. 90). Frente al mandato de Platón en República de expulsar 
a bailarines y poetas de la ciudad por el poder mimético que conllevan sus artes, los efectos del buen gobierno renacentista son representados con un grupo de ciudadanos bailando en corro en el primer plano del fresco. ${ }^{10}$ Sin embargo, esta imagen renacentista -heredera de la Grecia arcaica-de unidad social responde a un ideal de concordia a través de la igualdad y la justicia, no a una experiencia estética de lo ligero. Por el contrario, en la imagen del grupo danzante de Nietzsche, la cual tiene lugar fuera de los muros de la polis, no hay específicamente un ideal cívico. El baile no nos habla de una experiencia de celebración de la justicia social, sino de una emoción estética de fusión y armonía momentánea entre seres humanos. El baile en este capítulo de Ađí babló Zaratustra articula una comunidad apolítica, configurándose como un orden externo a la ciudad que no se pergeña en la polis ni tampoco sirve para dibujarla.

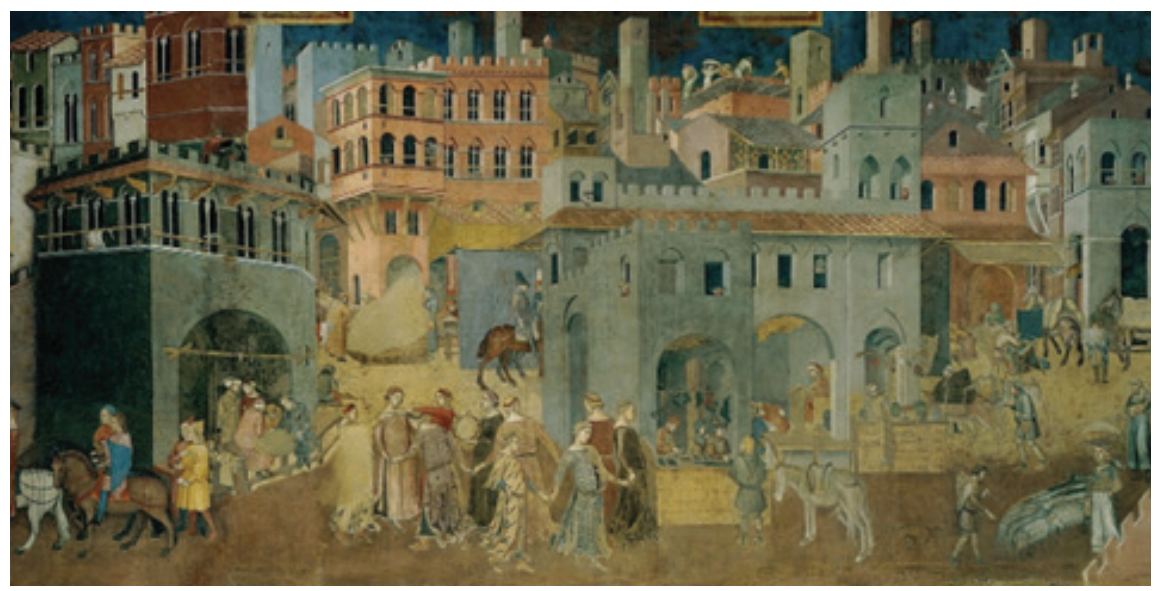

Figura 3. Ambrogio Lorenzetti (1338-40), Effettidel Buon Governo in città [ciclo di affreschi], Sala della Pace, Palazzo Pubblico, Siena. Wikimedia Commons.

Aquí, además, hay que tener en cuenta tanto las críticas a la ciudad como las críticas al socialismo que ya aparecían tanto en obras intermedias anteriores a la publicación de Ađí habló Zaratustra (1883-1885), como en posteriores publicaciones como Más allá del bien y del mal (1886). Por un lado, la vocación disidente de Nietzsche introducía en Humano demasiado humano (1878) el concepto de «filosofía del antimeridiano», para referirse a la sabiduría de aquellos que no habían encontrado su hueco 
en la ciudad y a quienes esperan «otras regiones» más propias de «espíritus libres».

[...] tal hombre tendrá que pasar noches en que, sintiéndose cansado, hallará cerrada la puerta de la ciudad donde buscaba el descanso; [...] Tal sucede frecuentemente al viajero; pero en compensación, contempla otras regiones y otros días, las brumas de los montes y los corazones de las musas que avanzan danzando a su encuentro, en los cuales un poco más tarde, cuando plácido, en el equilibrio del alma, se pasee por la mañana bajo los árboles, verá caer a sus pies de sus copas y sus ramas los dones saludables de los espíritus libres de lo que tienen su morada en la montaña, en la selva y en la soledad, y que así como él son viajeros y filósofos a su manera, tan pronto alegre y ligera, tan pronto reflexiva. Nacidos entre los misterios matinales, piensan en lo que puede recibir del día, entre el décimo y duodécimo sonido de la campana que da las horas, un rostro purísimo, radiante de luz, gozoso por su aureola de claridad: buscan la filosofía del antimeridiano. (eKGWB/MA-II; Nietzsche, 2011, pág. 71)

Asimismo, hay en Nietzsche un fuerte escepticismo hacia lo comunitario en Más allá Jel bien y del mal (1886). Siguiendo la lectura de Valadier (1982, pág. 98), Nietzsche consideraba a las masas gregarias o a los movimientos político-sociales síntomas de una moral compasiva débil, más propia de esclavos que de la aristocracia ética de los señores. ${ }^{11}$ Esta interpretación de Valadier se apoya en diferentes pasajes de la obra nietzscheana, concretamente en los párrafos 21 y 202 de Más allá del bien y del mal, en los que Nietzsche criticó la debilidad del concepto de «compasión socialista» (sozialistisches Mitleid) y expresó su reticencia hacia las propuestas socialistas, lo cual nos mostraría un abismo entre los iniciales presupuestos comunitarios y fraternales de El nacimiento de la tragedia frente al desencanto con lo colectivo a partir de Asíbabló Zaratustra y su alabanza a los «espíritus libres», desengaño que se confirmará con la imagen zaratustriana de la «estrella danzarina».

Estos últimos, cuando escriben libros, suelen asumir hoy la defensa de los criminales; una especie de compasión socialista es su disfraz más agradable. Y de hecho el fatalismo de los débiles de voluntad se embellece de modo sorprendente cuando sabe presentarse a sí mismo como 
la religión del sufrimiento humano: ése es su «buen gusto». (eKGWB/ JGB-21; Nietzsche, 1968, pág. 30)

[...]; coinciden en la creencia en la moral de la compasión comunitaria, como si ésta fuera la moral en sí, la cima, la alcanzada cima del hombre, la única esperanza del futuro, el consuelo de los hombres de hoy, la gran redención de toda culpa de otro tiempo: -coinciden todos ellos en la creencia de que la comunidad es redentora, por lo tanto, en la fe en el rebaño, en la fe en «sí mismos»... (eKGWB/JGB-202; Nietzsche, 1968, págs. 127-128)

Asimismo, tal y como recoge la interpretación de Reale y Antiseri (2016, pág. 381) de una cita de Nietzsche, resultaría difícil hacer una lectura en tono cívico o político al modo de la metáfora renacentista de la pequeña comunidad de bailarinas de Así habló Zaratustra, pues Nietzsche mantuvo una postura crítica con el Estado: «El más frío de todos los monstruos se llama «Estado». También es frío en el mentir, y la mentira que sale de su boca es la siguiente: «Yo, el Estado, soy el pueblo».» En este sentido, la articulación de una comunidad dionisíaca a través del baile en Así babló Zaratustra no se trataría de una comunidad política en sentido estricto, pues no son ciudadanos los que se aúnan sino, si acaso, una propuesta alternativa a la organización política -idea que se verá perfilada en las comunas libres del Lebensreformbewegung a principios de siglo XX (véase Clark, 2000, pág. 63; König, 1990)-. Asimismo, si miramos la trayectoria vital del inicial representante del dionisismo, se observa ya un escepticismo latente hacia lo comunitario en El nacimiento de la tragedia: no podríamos hablar de un ideal político en la experiencia dionisíaca, pues Arquíloco -representante del poeta lírico dionisíacoprioriza el deseo y la individualidad antes que la ciudad y el heroísmo, pues el poeta lírico por antonomasia abandona el campo de batalla, tirando su escudo, para así poder huir y salvar la vida.

\section{LA SOLEDAD CÓSMICA DE LA ESTRELLA DANZARINA}

Este escepticismo hacia lo comunitario y la apertura de un dionisismo cósmico más allá de lo grupal, se concretará en una metáfora de danza individualista: el solo de la «estrella danzarina». Esta imagen 
inicia su andadura en el prólogo de Ađí habló Zaratustra: «Yo os digo: es preciso tener todavía caos dentro de sí para poder dar a luz una estrella danzarina» (eKGWB/Za-I-Vorrede-5; Nietzsche, 1981, pág. 39). En esta nueva metáfora, ya no se trataría de hermanarse con la comunidad humana, no hablamos de un dionisismo antropológico propio de la experiencia de las masas, sino de un dionisismo inorgánico o cósmico.

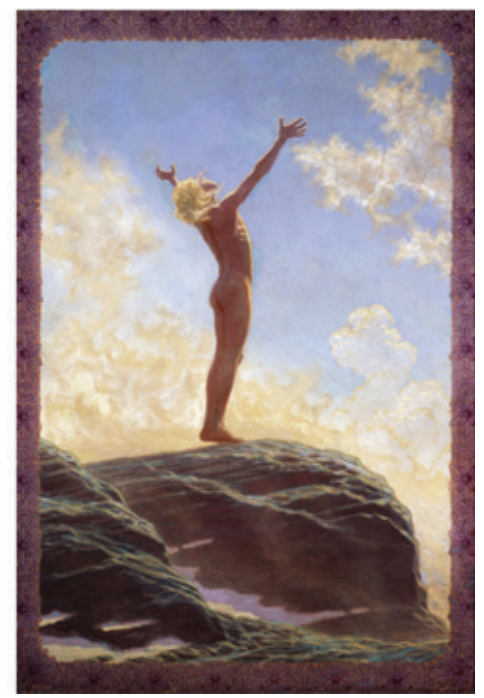

Figura 4. Hugo Höppener «Fidus»

(1894), Lichtgebet [Óleo sobre lienzo],

150 x $100 \mathrm{~cm}$. Museo Histórico

Alemán, Berlín. Wikimedia

Commons.

Estas inquietudes ya aparecían apuntadas en algunos extractos de El nacimiento de la tragedia, en los cuales se menciona un sentido de la embriaguez que excede a la fusión con la mera comunidad antropológica: «cualquiera se siente [...] Uno», «para supremo deleite de la unidad originaria», «se siente como un dios» (eKGWB/GT-1; Nietzsche, 2007, pág. 107), «la influencia mística de la enajenación de su individualidad» (eKGWB/GT-5; Nietzsche, 2007, pág. 128), «un poderoso sentimiento de unidad que conduce al mismo corazón de la naturaleza» (eKGWB/ GT-6; Nietzsche, 2007, pág. 141). En este nuevo sentido de la experiencia dionisíaca experimentamos una unión «metafísica» en el sentido de 
participación cósmica en lo Absoluto, no de un sentido de trascendencia ontológica o de experiencia de un afuera divino. Esto es lo que el filósofo de la religión Raimon Panniker denominó «experiencia mística», es decir, «una experiencia integral o comprehensiva de la realidad», «una experiencia de la realidad como un todo comprehensivo que no es simplemente la adición de sus partes o una noción formal» $\mathrm{o}$ «un acceso a la existencia como una realidad plena o totalidad» (Panniker, 2015, págs. 229-331).

Este tercer modo de experiencia dionisíaca nos hablaría de una suerte de experiencia espiritual o religiosa de comunión con el mundo; es decir, un estado de irrupción en el curso de la historia, el cual produce la fusión o unidad del sujeto con la totalidad o Absoluto. Esta suerte de abrazo cósmico o interés por lo Absoluto como experiencia de la totalidad aterrizada en lo corpóreo que excede la utopía socialista, aparece inicialmente en una serie de notas de 1881 bajo el título «Pensamientos principales», en las cuales comienza a despuntar el interés de Nietzsche por lo inorgánico:

¡El mundo muerto! ¡Eternamente movido y sin error, fuerza contra fuerza! ¡Y en el mundo sensible todo falso, presuntuoso! Es una fiesta pasar de este mundo al «mundo muerto».

¡Más allá de «mí» y de «ti»! ¡Sentir cósmicamente!

Mi tarea: la deshumanización de la naturaleza y luego la naturalización del hombre, una vez que ha logrado el concepto puro de «naturaleza.» (Nietzsche en Safranski, 2010, págs.. 242-243)

La metáfora de la estrella danzarina es, en primer lugar, una imagen que aúna las consecuencias de la muerte de Dios enunciada en La gaya ciencia (1882), pues ese caos constituyente de la estrella danzarina lo que muestra es «una pérdida de todo punto de referencia» (Reale/ Antiseri, 2016, pág. 387). «Dar a luz» una estrella danzarina no significa evitar el dolor, sino aceptar la vida en su totalidad y en la ausencia de sentido trascendente. Se trata de aceptar con un gran sí a la vida, sin prescindir de la materialidad en pos de una realidad trascendente o un Dios más allá del mundo. Es el concepto de amor fati que Nietzsche desarrolla en el capítulo «Antes de la caída del sol» de Así habló Zaratustra. El ser humano que ha alcanzado la sabiduría dionisíaca asume que está perdido en la 
inmensidad y que, al mismo tiempo, pertenece a la misma. Ese hombre ya no está buscando una razón trascendente que explique este laberinto e inmensidad cósmicas. Por el contrario, acepta el caos y se enseñorea en ese ser una extraviada «estrella danzarina» en el laberinto cósmico. Ya no busca una verdad irrefutable que sostenga un orden para el universo y la existencia o, como Nietzsche expresó en un fragmento de 1882-83 recurriendo a otra metáfora: «Un hombre laberíntico no busca nunca la verdad, sino sólo su Ariadna»(eKGWB/NF-1882, 4[55]).

Esta interpretación de la imagen de la estrella danzarina como metáfora del individuo dionisíaco es apoyada por la lectura de Nietzsche de Valadier (2015, pág. 537), quien propuso que el individuo dionisíaco es «aquel sujeto que sigue su camino desde una posición particular y está, al mismo tiempo, dominado por la inmensidad.» Asimismo, esta imagen de la cosmicidad como modo de existencia errática va a heredarse en María Zambrano, quien encontró en la condición del exiliado -aquel disidente que vive sin patria ni Estado- una condición que, si bien es desoladora e indeseable, supone también un alimento que nutre la vocación creadora.

Creo que el exilio es una dimensión esencial de la vida humana, pero al decirlo me quemo los labios, porque yo querría que no volviese a haber exiliados, sino que todos fueran seres humanos y a la par cósmicos, que no se conociera el exilio. (Zambrano, 2009, pág. 66)

Esta referencia a la sabiduría dionisíaca como una suerte de soledad cósmica, no solo se encuentra en el prólogo de Ađú babló Zaratustra, sino también en el capítulo «Del camino del creador», en el que nuevamente aparece la metáfora de la estrella danzarina como imagen de una sabiduría y soledad cósmicas que no pueden compartirse con el grupo y, aun menos, con la ciudad, como Zaratustra, quien comienza su periplo al ser ridiculizado como un funambulista o «bailarín de hilo» (Seiltanzer).

¿Quieres marchar, hermano mío, a la soledad? ¿Quieres buscar el camino que lleva a ti mismo? Detente un poco y escúchame.

«El que busca, fácilmente se pierde a sí mismo. Todo irse a la soledad es culpa»: así habla el rebaño. Y tú has formado parte del rebaño durante mucho tiempo. [...] Terrible cosa es hallarse solo con el juez y vengador 
de la propia ley. Así es arrojada una estrella al espacio vacío y al soplo helado de la soledad [des Alleinseins].

Hoy sufres todavía a causa de los muchos, tú que eres uno solo: hoy conservas aún todo tu valor y todas tus esperanzas. [...]

Mas alguna vez la soledad [Einsamkeit] te fatigará, alguna vez tu orgullo se curvará y tu valor rechinará los dientes. Alguna vez gritarás «iestoy solo [allein]!»

Tú caminas por encima de ellos; pero cuanto más alto subes, tanto más pequeño te ven los ojos de la envidia. El más odiado de todos es, sin embargo, el que vuela. [...]

Injusticia y suciedad arrojan ellos al solitario [nach dem Einsamen]: pero, hermano mío, si quieres ser una estrella, ¡no tienes que iluminarlos menos por eso!

¡Y guárdate de los buenos y justos! Con gusto crucifican a quienes se inventan una virtud para sí mismos, -odian al solitario [den Einsamen]. (eKGWB/Za-I-Schaffender; Nietzsche, 1981, pág. 101-103) ${ }^{12}$

\section{Conclusiones}

La imagen de la estrella danzarina es el final de un ciclo de posibles modos de lo dionisíaco a través de la danza que se inicia en El nacimiento de la tragedia, el cual pasa de la inicial presuposición comunitaria y masiva del dionisismo, a la pequeña comunidad apolítica de Así babló Zaratustra y llega hasta la reivindicación de la individualidad y disidencia solitaria en la sabiduría dionisíaca. El inicial socialismo estético del fenómeno dionisíaco -la realización extática a través de la experiencia de la multitud-se va abandonando progresivamente hasta llegar a una suerte de soledad cósmica que excede no solo a la pequeña comunidad sino también a los márgenes de la ciudad y el Estado. Dioniso, frente a la inicial algarabía y hermanamiento colectivos de El nacimiento de la tragedia, acaba por ser un dios disidente y solitario en Asíbabló Zaratustra. 
Bibliografía

Argullol, Rafael (1991). La atracción del abismo. Un itinerario por el paisaje romántico. Barcelona: Ediciones Destino.

Baudelaire, Charles (2016). Spleen de París, edición bilingüe de Enrique López Castellón. Madrid: Abada Editores.

Baxmann, Inge (1999). Gemeinschaft. Körper- una Tanzkulturen in Jer Moderne. München: Fink.

Clark, Toby (2000). Arte y propaganda en el siglo XX, traducción de Isabel Balsinde. Madrid: Akal.

De Santiago Guervós, Luis E. (2004). Arte y poder. Aproximación a la estética de Nietzsche. Madrid: Trotta.

Detienne, Marcel (2003). Dioniso a cielo abierto. Un itinerario antropológico en los rostros y las moradas del dios del vino, traducción de Margarita Mizraji. Barcelona: Gedisa.

Digitale kritische Gesamtausgabe von Nietzsches Werke und Briefen (eKGWB) (2018). [Archivo online de obras y cartas de Nietzsche en alemán] Recuperado de: http://www.nietzschesource. org.

Eurípides (2003). Andrómaca. Heracles Loco. Las Bacantes, introducción, traducción y notas de Francisco Rodríguez Adrados. Madrid: Alianza Editorial.

González García, José María (2016). La mirada de la justicia. Madrid: Antonio Machado Libros.

Hanse, Oliver (2010). À l'ecole du rythme: utopies communitaires allemandes autour de 1900. Saint-Étienne: Publications de l'Université de Saint-Etienne.

Harvey, David (2008). París: capital de la modernidad, traducción de José María Amoroto Salido. Madrid: Akal.

Homero (1971). Odisea, prólogo de Mercedes Castellanos. Barcelona: Editorial Juventud.

Homero (1972). Ilíada, prólogo de Antonio Tovar. Barcelona: Editorial Juventud.

Keats, John (1982). Sonetos, odas y otros poemas, ensayo preliminar de Matthew Arnold, selección, traducción literal y notas de José María Martín Triana. Madrid: Visor.

König, Oliver (1990). Nackheit. Soziale Normierung und Moral. Darmstadt, Opladen: Westdeutscher Verlag. 
Grimal, Pierre (1979). Diccionario de mitología griega y romana. Barcelona: Paidos.

Lamothe, Kimberli (2003). Giving Birth to A Dancing Star: Reading Friedrich Nietzsche's Maternal Rhetoric via Isadora Duncan's Dance. Soundings: An Interdisciplinary Journal, Vol. 86, № 3/4, 351-373.

Lipovetsky, Gilles (2016). De la ligereza. Barcelona: Anagrama.

Lomba, Pedro (2014). Márgenes de la modernidad. Libertinismo y filosofía en el siglo XVII. Madrid: Escolar y Mayo.

Mas Torres, Salvador (2014). Alemania y el mundo clásico (1896-1945). Madrid: Plaza y Valdés.

Mateos de Manuel, Victoria (2016). Mediodía: Nietzsche y la cuestión del tiempo. Sobre el sentido de presente en la filosofía. Estudios Nietzsche, $\mathrm{n}^{\circ}$ 16, 73-90.

Mavromataki, Maria (1997). Greek Mithology and Religion. Atenas: Haitalis.

Nietzsche, Friedrich (1968). Werke: Kritische Gesamtausgabe Abt. 6, BJ. 2, Jenseits von Gut und Böse; Zur Genealogie der Moral (1886-1887), edición de Giorgio Colli y Mazzino Montinari. Berlin: Walter de Gruyter.

Nietzsche, Friedrich (1981). Ađí babló Zaratustra, trad. de Andrés Sánchez Pascual. Madrid: Alianza Editorial.

Nietzsche, Friedrich (2007). El nacimiento de la tragedia, O belenismo y pesimismo, edición de Germán Cano. Madrid: Biblioteca Nueva.

Nietzsche, Friedrich (2011). El viajero y su sombra. Segunda parte de Humano, demasiado humano, trad. de Carlos Vergara. México: Biblioteca Edaf.

Panniker, Raimon (2015). Mústica y espiritualidad. Tomo 1. Mústica, plenitud de vida. Barcelona: Herder.

Platón (1986). República, ed. de Conrado Eggers Lan. Madrid: Editorial Gredos.

Pujals, Esteban (1988). Historia de la literatura inglesa. Madrid: Gredos.

Reale, Giovanni/ Antiseri, Dario (2016). Historia del pensamiento filosófico y científico. III. Del Romanticismo hasta hoy. Barcelona: Herder.

Safranski, Rüdiger (2010). Nietzsche. Biografía de su pensamiento, traducción de Raúl Gabás. Barcelona: Tusquets.

Sánchez Mariño, Diego (2014). Injertando a Dioniso. Las interpretaciones del dios, de nuestros días a la Antigüedad. Madrid: Siglo XXI. 
Sartre, Jean Paul (1994). Baudelaire. Madrid: Alianza Editorial.

Schulze, Hagen (2001). Breve bistoria de Alemania. Madrid: Alianza Editorial.

Signes Codoñer, Juan (ed.) (2005). Antiquae Lectiones. El legado clásico desde la Antigüedad hasta La Revolución Francesa. Madrid: Cátedra. Sloterdijk, Peter (2000). El pensador en escena. El materialismo de Nietzsche, traducción de Germán Cano. Valencia: Pre-textos.

Tatarkiewicz, Wladyslaw (1987). Historia de la Estética. I. La Estética Antigua, traducción de Danuta Kurzyca, Rosa Ma Mariño Sánchez-Elvira y Fernando García Romero. Madrid: Akal.

Valadier, Paul (1982). Nietzsche y la crítica del cristianismo, traducción de Eloy Rodríguez Navarro. Madrid: Ed. Cristiandad.

Zambrano, María (2009). Las palabras del regreso. Madrid: Cátedra.

\section{NOTAS}

1 Hay, al menos, dos sucesos en que aparece el carácter polimórfico del dios Dioniso. En primer lugar, Dioniso fue convertido en cabrito en Nisa, donde pasó su infancia criado por las ninfas, con «el objeto de evitar que Hera lo reconociese» (Grimal, 1979, pág. 140). Asimismo, en la tragedia de Eurípides Las Bacantes, Dioniso acontece ante Penteo no como un dios, estatuto que se está poniendo en entredicho, sino como un «extranjero afeminado» (Eurípides, 2003, pág. 201) -según las palabras de Penteo-. Sobre los diferentes significados históricos de los dionisíaco acúdase a Detienne (2003) y Sánchez Mariño (2014).

2 Tanto lo apolíneo como lo dionisíaco se presentan en El nacimiento de la tragedia como «estados estéticos de la naturaleza» (Kunstzustände der Natur), los cuales pertenecen al hombre sólo en cuanto que el artista es «imitador» de la naturaleza (ist jeder Künstler «Nachahmer»). Lo apolíneo y lo dionisíaco son, por lo tanto, estados asubjetivos, independientes del individuo y originarios, de los que el individuo puede, a pesar de ello, formar parte en cuanto que estos estados son «impulsos artísticos»o «un rasgo sentimental» (Kunsttriebe der Natur, ein sentimentaler Zug) de una naturaleza de la que el individuo es también miembro y puede acceder a través de la mediación del arte. Lo apolíneo y lo dionisíaco no son, en consecuencia, expresiones propiamente humanas, sino más bien expresiones primitivas que pueden darse en lo humano, que lo atraviesan sin pertenecerle (eKGWB/GT-2; 
Nietzsche, 2007, págs. 108-109). Esta comprensión de los estados apolíneo y dionisíaco es una clara herencia ontológica del Romanticismo inglés. Para John Keats, como muestra en el poema «Where's the Poet», el poeta romántico no es un ser dotado para transmitir un conocimiento filosófico y moral, sino que es aquel capaz de olvidarse de sí para sumergirse en la realidad; el poeta elimina su yo y se introduce en la verdad de las cosas; no cuenta en el poema cómo él, hombre particular, observa al tigre, sino que trae al poema, participa a través de la escritura del «bramido del tigre» mismo (Keats, 1982, pág. 84; Pujals, 1988, págs.. 333-340).

3 La vinculación específica entre danza y experiencia dionisíaca aparece en El nacimiento de la tragedia:

«Con sus dos divinidades artísticas, Apolo y Dioniso, se relaciona nuestro conocimiento de que el mundo helénico se define por un monstruoso antagonismo, en orígenes y fines, entre el arte plástico, apolíneo, de un lado, y el arte no plástico de la música, el arte de Dioniso, del otro. [...] esta fusión engendran la obra artística -dionisiaca a la par que apolínea-de la tragedia ática.» (eKGWB/GT-1; Nietzsche, 2007, págs.. 100-101).

4 Lamothe se refiere específicamente a la conjunción entre las expresiones «dar a luz»y «estrella danzarina» que aparece en el prólogo de Así habló Zaratustra: «Yo os digo: es preciso tener todavía caos dentro de sí para poder dar a luz una estrella danzarina.» (eKGWB/Za-I-Vorrede-5; Nietzsche, 1981, pág. 39) Lamothe (2003, pág. 353) considera que el uso de la metáfora del parto en el caso de la danza es una forma de poner en valor el cuerpo y de «revaluing Christian values: It means coming to value bodily being ( $\partial_{e} r$ Leib) as a "great reason [grosse Vernunft]... that does not say 'I' but does 'I'». Asimismo, además de los usos textuales de la danza en Nietzsche, son de reseñar dos anécdotas biográficas que muestran la admirable peculiaridad vital de Nietzsche. Según la casera del hogar en Turín donde residió Nietzsche, quien le observó a través de la cerradura de la puerta, este bailó en una ocasión desnudo en su cuarto. Asimismo, entre 1889 y 1890, estando ya en el psiquiátrico de Jena, Nietzsche bailó al sonido de la cítara hasta que un encargado del asilo mental logró calmarle. Véase K. King, «The Dancing Philosopher», Topoi, vol. 24, 2005, págs. 103-111; R. Safranski, Nietzsche. Biografía de su pensamiento, traducción de Raúl Grabás, Barcelona: Tusquets, 2010, pág. 48.

5 El vitalismo de fin de siglo (Lebensphilosophie) surgió como oposición a la Kathederphilosophie o filosofía de sillón o cátedra, la cual era considerada como la responsable intelectual de despersonalización de las relaciones 
humanas, la mecanización generalizada de la sociedad y el progreso de la razón industrial. La Kathederphilosophie era considerada generadora de arritmia y desestructuración, produciendo un cuerpo social enfermo. Por el contrario, el ritmo y el encomio de la danza propios de la Lebensphilosophie eran considerados «marca de las fuerzas vitales originales que residen en cada individuo» $\mathrm{y}$ «fuerza creadora de valores» (Hanse, 2010, pág. 11). En este contexto, surgieron diversas utopías rítmicas en el fin de siglo bajo el paraguas ideológico del romanticismo anticapitalista como la Comuna Monte Veritá o el desarrollo del Lebensreformbewegung en Alemania (véase Baxmann, 1993).

6 Al respecto, es destacable el carácter de mistificación e hibridación que existe en la revitalización de la polaridad dionisíaco-apolíneo del mundo antiguo a través de Nietzsche.

En el período arcaico de la estética griega (s. VI-V a.C.), como explica Tatarkiewicz (1987, págs. 19-35), el arte quedaba dividido en dos ramas. Por un lado, una modalidad expresiva a la que pertenecían la poesía, la música y la danza, modos que constituyen lo que Nietzsche denominará arte dionisiaco o Zielinski triunica choreia. Por otro lado, una vertiente constructiva, constituida por la arquitectura, la escultura y la pintura.

Inicialmente la danza tenía un valor catártico, siendo una herramienta sanadora y de culto que «constituía no sólo una ceremonia de los sacerdotes, sino también un espectáculo para las masas. Originalmente, fue el arte principal de los griegos, que no poseían todavía una música independiente por sí sola, ejecutada sin gestos y movimientos» (Tatarkiewicz, 1987, pág. 23). No obstante, si bien la danza contaba con un reconocido estatuto social en el mundo griego, el mundo romano desarrolló un modo libertino de la danza que nada gustó a la Iglesia, estereotipo bajo el cual la danza quedó condenada en el Medievo, si bien han llegado documentos de danzas o imágenes populares como la entrega extática en el baile de San Vito, tema que menciona Nietzsche en El Nacimiento de la Tragedia, o la alegoría de la Danza Macabra o Danza de la Muerte, a la que Baudelaire también dedica un poema en Las flores del mal (1857).

Por ello, hay que remarcar que el imaginario que construye Nietzsche de lo dionisíaco en el mundo griego se basa no en una herencia propiamente antigua, sino medieval que él considera reflejo del mundo antiguo. Asimismo, esta recuperación del mundo clásico que lleva a cabo Nietzsche se inserta históricamente en el contexto de producción de sentido del concepto de «nación alemana»: el Romanticismo alemán, y su constante recuperación y 
dación de sentido del mundo clásico, van a funcionar como el corchete cultural para la fijación de «lo alemán» a lo largo del siglo XIX. Se trató de presentar a Alemania como la «nueva Grecia» por su «inaudito florecimiento cultural», mientras que Francia representaría a una Roma contemporánea (Schulze, 2001, pág. 96). Sobre los procesos de hermenéutica histórica en la construcción de lo clásico véase Mas Torres (2014) y Signes Codoñer (2005).

7 No obstante, en la comparación del uso de la multitud en Nietzsche y Baudelaire es interesante recalcar la diferencia entre ambos autores. Mientras que para Nietzsche la multitud dionisíaca supone una pérdida de la individualidad, en Baudelaire -siguiendo la lectura de Sartre (1994, pág. 117)la multitud le sirve al flâneur para individualizarse a través de la fusión con la alteridad.

«Ese es el fin de los esfuerzos de Baudelaire: apoderarse de sí mismo, en su eterna diferencia, realizar su Alteridad identificándose con el mundo entero. Aligerado, vacío, lleno de símbolos y de signos, ese mundo que lo envuelve en su inmensa totalidad no es sino él mismo.»

8 Obsérvese, al respecto, la siguiente cita de Lidsky en Harvey (2008, pág. 369):

«Poco antes de la Comuna, Edmond de Goncourt anotó en su diario: «hablan de la nerviosa sobreexcitación de la mujer [...] del temor a tener que sofocar revueltas de mujeres». Después de la Comuna, ese miedo se convirtió en la leyenda de «mujeres siniestras», de «amazonas y viragos, inspirando e inflamando a los hombres con su inmodestia obscena y desvergonzada [...] los vestidos desabrochados, sus pechos prácticamente desnudos» incitando y dirigiendo el incendio de París. Contemplando los cuerpos de las mujeres sacados de casas y barricadas y sumariamente ejecutadas, Houssay escribió: «Ni una sola de esas mujeres tenía un rostro humano, solamente la imagen del vicio y del crimen. Eran cuerpos sin alma, merecedores de mil muertes incluso antes de recibir el petróleo. Solamente hay una palabra para retratarlas: horrendas.»»

Estos relatos atemorizantes sobre la Comuna de París también nos han llegado no sólo a través de los escritores franceses, sino a través de la política alemana coetánea a la gestión de París por un gobierno popular durante un período de cuatro meses en 1871 . El 28 de enero de 1871 se firmaba el armisticio entre Francia y Prusia, dándose por finalizada la Guerra FrancoPrusiana que había dado comienzo en 1870. Con ello, se inauguraba el Imperio Alemán. El ejército prusiano, vencedor del conflicto bélico, rodeó 
la capital francesa y fue testigo de la Comuna de París. Las revoluciones de 1830 y 1848, que habían comenzado también en París, se extendieron por toda Europa -en Alemania tuvo lugar lo que se conoce como «Revolución de Marzo». Tras contemplar los sucesos de la Comuna, las tropas alemanas consideraron que un acontecimiento de este calibre no debía ocurrir bajo ninguna circunstancia en Alemania y Otto von Bismarck, canciller (Kanzler) entre 1871 y 1890 , se encargó de generar medidas políticas que evitasen las revueltas de masas: Realpolitik y Kulturkampf, destacando la creación del estado social alemán para impedir una revolución proletaria (Schulze, 2001, pág. 150-151).

9 La metáfora de los «pies ligeros» es una imagen propia de la Grecia arcaica, la cual encontramos en sendos poemas épicos de Homero, tanto en Ilíada como en Odisea. En primer lugar, Aquiles, héroe de la guerra de Troya, era conocido como el de «los pies ligeros» por su capacidad para correr, característica fundamental para el guerrero de la época (Homero, 1972, pág. 26). Además, su punto débil estaba también relacionado con el pie, el famoso «talón de Aquiles», metáfora para hablar de la doble cara de la vulnerabilidad: es precisamente en la debilidad donde reside también la fortaleza del individuo, Aquiles es inmortal porque su madre Tetis le sujetó del talón para sumergirle en el río Estigia (Mavromataki, 1997, págs.. 34-36).

Asimismo, en Odisea el baile masculino y su ligereza de pies aparece como símbolo de heroicidad aristocrática y carácter marinero, más que luchador. Esto se observa cuando Ulises llega a la isla de los feacios, donde el rey le ofrece una fiesta en su honor y los bailarines dicen:

"No somos irreprensibles púgiles ni luchadores, sino muy ligeros en el correr y excelentes en gobernar las naves, y siempre nos placen los convites, la cítara, los bailes, las vestiduras limpias, los baños calientes y la cama. Pero, ea, danzadores feacios, salid los más hábiles a bailar [...] deslumbradores movimientos que con los pies hacían.» (Homero, 1971, págs. 115-116)

En «La canción de los sepulcros» Nietzsche (1981, pág. 168) se refiere a Aquiles cuando dice: «Invulnerable soy únicamente en mi talón». Además, la cuestión de la ligereza en Nietzsche no aparece sólo asociada a los pies, sino que se convierte en un tema propuesto a través de otras metáforas, todas ellas pertenecientes al capítulo de Así babló Zaratustra «Del espíritu de la pesadez»: la Tierra es bautizada como «la ligera», el avestruz corre más deprisa que el caballo, se necesitan ágiles piernas para escalar mástiles. Cabe también citar el siguiente fragmento, en el que se observa una progresión entre las acciones de caminar, correr, trepar, bailar y volar: 
«Y esta es mi doctrina: quien quiera aprender alguna vez a volar tiene que aprender primero a tenerse en pie y a caminar y a correr y a trepar y a bailar: -el volar no se coge con el vuelo-.» (Nietzsche, 1981, pág. 272)

Nietzsche vuelve a revalorizar la metáfora de la ligereza tan presente en el mundo antiguo, en un momento histórico en que este valor estético estaba desacreditado. Nietzsche contrapone dos ideales de vida. Por un lado, nos encontramos el espíritu de la pesadez, reflejo de la cualidad del pensamiento, el cual -cargante, macizo, quieto, soporífero, afligido, severo y fastidioso- es incapaz de participar de las bondades del baile. La danza, por el contrario, ejemplifica el espíritu de la ligereza; es decir, aquello que es liviano, alegre y grácil, gustoso de ser vivido. En Nietzsche lo ligero se identifica con lo gozoso de la existencia. La pesadez, por el contrario, es una aguafiestas. Ser ligero es fuente de halago. Resultar pesado, por el contrario, se trata de un agravio. Con ello, Nietzsche está invirtiendo los valores propios anteriores al mundo contemporáneo en que, como señala Lipovetsky (2016, pág. 8), «lo pesado evocaba lo respetable, lo serio, la riqueza; lo ligero, la baratija, la falta de valor.» Sobre la cuestión de la ligereza en Nietzsche véase también Mateos de Manuel (2016).

10 A continuación, reproducimos el fragmento en el que Platón conmina a expulsar a bailarines y artistas de su modelo perfecto de ciudad-estado: «Porque aquel Estado sano no es ya suficiente, sino que debe aumentarse su tamaño y llenarlo con una multitud de gente que no tiene ya en vista las necesidades del Estado. Por ejemplo, toda clase de cazadores y de imitadores, tanto los que se ocupan de figuras y colores cuanto los ocupados en la música; los poetas y sus auxiliares, tales como los rapsodas, los actores, los bailarines, los empresarios; y los artesanos fabricantes de toda variedad de artículos, entre otros también de los que conciernen al adorno femenino. Pero necesitaremos también más servidores. ¿O no te parece que harán falta pedagogos, nodrizas, institutrices, modistas, peluqueros, y a su vez confiteros y cocineros? Y aún necesitaremos porquerizos. Esto no existía en el Estado anterior, pues allí no hacía falta nada de eso, pero en éste será necesario. Y deberá haber otros tipos de ganado en gran cantidad para cubrir la necesidad de comer carne.» (Platón, 1986, pág. 128)

11 PÁG. Valadier, Nietzsche y la crítica del cristianismo, trad. de Eloy Rodríguez Navarro, Madrid: Ed. Cristiandad, 1982, pág. 98.

12 Además de las mencionadas críticas frontales a los comunitario, Nietzsche alabó la soledad en diferentes pasajes de su obra, los cuales están en 
coherencia con la reivindicación de la imagen de la estrella danzarina como aspiración de la sabiduría dionisíaca.

«Una soledad tranquila y amistosa conmigo mismo, en buenos pensamientos y risas -como yo también soy-.» (eKGWB/ NF-1877, 22[73]

«Estar solo es el más valioso de mis métodos de cura, jasí que no os acongojéis! Si en verano no me va mejor, dejo la universidad» (Carta a Franziska y Elisabeth Nietzsche del 9/2/1879, KGWB/BVN-1879, 802)

«Hombres solitarios. -Algunos hombres están tan acostumbrados a estar solos consigo mismos, que no se comparan a los demás, sino que desarrollan el monólogo de su existencia en un estado de espíritu apacible y alegre, en conversaciones y hasta en risas a solas. Pero si se les lleva a compararse con otro, se inclinan a una sutil depreciación de ellos mismos, hasta el punto de que es necesario forzarlos a volver a tomar de otros una buena y justa idea de sí, y todavía, de esa idea tomada, quieren siempre retirar y corregir algo. Es necesario, pues, conceder a ciertos hombres su soledad y no lamentarla neciamente.» (eKGBW/HH-622; Nietzsche, 2011, pág. 364) 